\title{
Oral glucose lowering drugs in type 2 diabetic patients with chronic kidney disease
}

\author{
Cláudia Nogueira, ${ }^{1,2}$ Selma B. Souto, ${ }^{3}$ Eduardo Vinha, ${ }^{1}$ \\ Daniel Carvalho-Braga, ${ }^{1,2}$ Davide Carvalho ${ }^{1,2}$
}

${ }^{1}$ Department of Endocrinology, Diabetes and Metabolism, Centro Hospitalar Sāo Joāo, ${ }^{2}$ Faculty of Medicine, University of Porto, Porto, ${ }^{3}$ Department of Endocrinology, Hospital de Braga, Braga, Portugal

\begin{abstract}
Chronic kidney disease (CKD) represents a challenge in the treatment of type 2 diabetic patients. Renal impairment may affect drug clearance and other pharmacokinetic processes which can increase toxicity and drug to drug interactions or cause ineffective therapy. There are many oral glucose lowering drugs available for the treatment of type 2 diabetes mellitus (T2DM) with different mechanisms of action and different pharmacokinetic profiles. While all classes may be used in patients with mild renal impairment, therapeutic options for patients with moderate to severe CKD are still limited. This review focuses on the pharmacokinetics, metabolism, and safety of oral glucose lowering drugs in patients with T2DM and CKD.
\end{abstract}

Key words: Chronic kidney disease, Oral glucose lowering drugs, Type 2 diabetes mellitus

\section{INTRODUCTION}

Type 2 diabetes mellitus (T2DM) is one of the most common metabolic disorders worldwide with its prevalence being unprecedented in both developed and developing countries. ${ }^{1}$ T2DM is the leading cause of end-stage renal disease (ESRD) all over the world, while patients with CKD of other etiologies may also develop T2DM. ${ }^{2}$ Management of T2DM in patients with renal impairment is a complex process that requires a comprehensive approach. Clinicians must be aware that as renal function worsens, abnormalities in glucose homeostasis develop, affecting secretion,

\section{Address for correspondence:}

Cláudia Nogueira

Alameda Prof. Hernâni Monteiro, 4200-319 Porto, Portugal Tel.: +351 916337 096, E-mail: cmaianogueira@gmail.com Received 03-10-2013, Accepted 21-11-2013 clearance, and peripheral tissue sensitivity to insulin. ${ }^{3}$ Several factors contribute to hyperglycemia, namely decreased insulin production and insulin resistance.

Accumulation of uremic toxins (which blunt ability to suppress hepatic gluconeogenesis), chronic inflammation, excess visceral fat, oxidative stress, and metabolic acidosis can all affect the insulin signaling pathway and induce insulin resistance. On the other hand, hypoglycemia may also develop in patients with advanced CKD due to accumulation of uremic toxins, which lead to lower hepatic and renal insulin degradation, and also as a result of decreased renal gluconeogenesis, uremic malnutrition, and deficient catecholamine release. Assessment of glucose control in patients with progressive kidney disease by measuring $\mathrm{HbA}_{1 \mathrm{c}}$ may also be a challenge. Falsely increased values may occur as a result of carbamyla- 
tion of the hemoglobin and acidosis. Meanwhile, reduced red blood cell lifespan, transfusions, and hemolysis may contribute to falsely reduced $\mathrm{HbA}_{1 \mathrm{c}}$ values. Nevertheless, $\mathrm{HbA}_{1 \mathrm{c}}$ remains the best clinical marker of long-term glycemic control, particularly if combined with self-monitoring of blood glucose. ${ }^{4}$ Glycated albumin, as an alternative, reflects glycemic control over a 2-week period and may be of greater value for predicting clinical outcomes in patients with advanced CKD. Besides considering the particularities of treating T2DM in patients with CKD, clinicians should also be aware of the therapeutic options. Many drugs are available for treatment of T2DM, namely biguanides, sulfonylureas (SUs), meglitinide analogues, thiazolidinediones (TZDs), alpha-glucosidase inhibitors, dipeptidylpeptidase-4 (DPP-4) inhibitors, dopamine receptor agonists, and in the near future sodium-glucose co-transporter (SGLTs) inhibitors and G-protein coupled receptor 40 agonists (GPR 40). Although all drugs can be used in patients with mild renal impairment, ${ }^{4,5}$ therapeutic options for patients with moderate to severe CKD or with ESRD are limited, since drug or metabolite accumulation may occur due to a reduced glomerular filtration rate (GFR) resulting in increasing side effects. In this case, some drugs are not recommended, while others can be used with dose adjustment. This paper reviews the pharmacokinetics, metabolism, and safety of oral glucose lowering drugs in patients with T2DM and CKD.

\section{ORAL HYPOGLYCEMIC DRUGS}

\section{Biguanides}

Metformin, the only available biguanide, is the first line drug in T2DM therapy. ${ }^{5}$ It acts mainly by decreasing hepatic glucose production, but also increases peripheral glucose uptake and reduces intestinal glucose production, improving glucose tolerance and lowering fasting and postprandial plasma glucose. ${ }^{6} \mathrm{It}$ is predominantly absorbed in the small intestine and its peak plasma concentrations are attained 3 hours after intake. Metformin does not bind to plasma proteins and it is excreted unchanged in urine. The elimination half-life $\left(t^{1 / 2}\right)$ is approximately 5 hours.

Metformin does not cause hypoglycemia nor weight gain ${ }^{5}$ and has been shown to reduce long- term diabetes complications, although the effect on macrovascular disease is controversial. ${ }^{7}$ In a metaanalysis of 35 randomized clinical trials, including 7,171 and 11,301 participants treated with metformin and comparator, respectively, metformin was associated with a reduction of cardiovascular risk when compared with placebo or no therapy, whereas its effect disappeared when active-comparator trials were included. ${ }^{8}$ The authors speculated that the cardiovascular protection conferred is related to the improvement of glucose control.

The most common adverse reactions to metformin are gastrointestinal but the most feared reaction, although rare, is lactic acidosis. ${ }^{5,9}$ A meta-analysis of 347 studies assessed the incidence of lactic acidosis in patients on metformin treatment for at least one month compared to placebo or non-metformin therapies. ${ }^{10}$ There were no cases of fatal or nonfatal lactic acidosis in 70,490 patient-years of metformin use or in 55,451 patients-years in the non-metformin group. The upper limit for the true incidence of lactic acidosis per 100,000 patient-years was 4.3 cases in the metformin group and 5.4 cases in the non-metformin group. In a subgroup of patients with mild to moderate $\mathrm{CKD}$, there was no difference in the incidence of lactic acidosis. Furthermore, there is no correlation between levels of metformin and lactate in patients with lactic acidosis, and its prognosis is mainly related to the severity of the underlying condition and comorbidities. ${ }^{9}$ The risk of lactic acidosis is enhanced by conditions that cause hypoxia and which predispose patients to lactate production and accumulation such, as heart failure and pulmonary chronic disease, or diseases that reduce lactate clearance (e.g. liver dysfunction).

The evidence suggests that metformin can be safely used in patients with creatinine $<1.5 \mathrm{mg} / \mathrm{dL}$. Since serum creatinine may overestimate renal function, calculation of the estimated GFR (eGFR) is preferred. The clearance of metformin decreases by about $75 \%$ when the eGFR is $<60 \mathrm{~mL} / \mathrm{min} / 1.73 \mathrm{~m}^{2}$ without additional changes when the eGFR declines to $30 \mathrm{~mL} /$ $\min / 1.73 \mathrm{~m}^{2} .^{11}$ At these levels of renal impairment, serum concentration of metformin is only about twofold higher than in normal kidney function. Current United Kingdom (UK) guidelines on the treatment of T2DM allow metformin use until an eGFR of $30 \mathrm{~mL} / \mathrm{min} / 1.73 \mathrm{~m}^{2}$ with dose reduction advised at 
$45 \mathrm{~mL} / \mathrm{min} / 1.73 \mathrm{~m}^{2} .^{9,12}$ In the USA, metformin is contraindicated for men with serum creatinine $\geq 1.5 \mathrm{mg} /$ $\mathrm{dL}$ and for women with serum creatinine $\geq 1.4 \mathrm{mg} /$ $\mathrm{dL} ;{ }^{5}$ eGFR calculated for these creatinine values ranges from $66 \mathrm{~mL} / \mathrm{min} / 1.73 \mathrm{~m}^{2}$ in a 20 -year-old man $\left(54 \mathrm{~mL} / \mathrm{min} / 1.73 \mathrm{~m}^{2}\right.$ in a 20 -year-old woman) to $43 \mathrm{~mL} /$ $\mathrm{min} / 1.73 \mathrm{~m}^{2}$ in an 80 -year-old $\mathrm{man}\left(36 \mathrm{~mL} / \mathrm{min} / 1.73 \mathrm{~m}^{2}\right.$ in an 80-year-old woman).

A recent observational study of 51,675 T2DM patients with a mean follow-up of 3.9 years supports the NICE guideline recommendations. ${ }^{13}$ A composite endpoint including acidosis, shock, acute renal failure and serious infections was used to evaluate the occurrence of lactic acidosis. Metformin, compared with any other treatment, showed reduced risks of acidosis/ serious infection and all-cause mortality in patients with eGFR $45-60 \mathrm{~mL} / \mathrm{min} / 1.73 \mathrm{~m}^{2}$, and no increased risks of all-cause mortality, acidosis/serious infection or cardiovascular disease were found in patients with eGFR $30-45 \mathrm{~mL} / \mathrm{min} / 1.73 \mathrm{~m}^{2}$. A prospective observa- tional study evaluated acute kidney injury and lactic acidosis in patients treated with metformin. ${ }^{14} \mathrm{~A}$ total of 29 cases were identified over 4 years; however, moderate renal impairment was not associated with a higher risk of dialysis-dependent acute kidney injury in patients who develop lactic acidosis and it seems not to influence prognosis. In this study, an episode of acute gastroenteritis precipitated the event in 26 cases, showing that volume depletion and hypoperfusion appear to aggravate the severity of metforminrelated metabolic acidosis when associated with an acute kidney injury.

Although the use of metformin in moderate CKD is still controversial, we think that its use should be avoided in patients with CKD stages 3-5 with other risk factors for lactic acidosis. In patients without risk factors, the available evidence suggests that metformin may be safely used without dose adjustment in CKD stage $3 \mathrm{~A}$ and with half-dose reduction in stage $3 \mathrm{~B}$ (Table 1). Patients should be encouraged to inter-

Table 1. Dosing adjustment for oral hypoglycemic drugs according to CKD stage

\begin{tabular}{|c|c|c|c|c|c|}
\hline \multirow[b]{2}{*}{ Class } & \multirow[b]{2}{*}{ Drug } & \multicolumn{4}{|c|}{ Chronic kidney disease stage (dialysis not included) } \\
\hline & & $\begin{array}{c}3 \mathrm{~A} \\
45-59 \mathrm{~mL} / \mathrm{min}\end{array}$ & $\begin{array}{c}3 B \\
30-44 \mathrm{~mL} / \mathrm{min}\end{array}$ & $\begin{array}{c}4 \\
15-29 \mathrm{~mL} / \mathrm{min}\end{array}$ & $\begin{array}{c}5 \\
<15 \mathrm{~mL} / \mathrm{min}\end{array}$ \\
\hline Biguanides & Metformin & No dose adjustment $^{1}$ & Half-dose $^{1}$ & Avoid & \\
\hline \multirow[t]{3}{*}{ Sulfonylureas } & Glibenclamide & \multicolumn{4}{|c|}{ Avoid } \\
\hline & $\begin{array}{l}\text { Glipizide } \\
\text { Gliclazide }\end{array}$ & \multicolumn{2}{|c|}{ No dose adjustment } & \multicolumn{2}{|c|}{ No dose adjustment ${ }^{2}$} \\
\hline & Glimepiride & Initiate at low dose $(1 \mathrm{mg})$ & & Initiate at low dose $(1 \mathrm{mg})^{2}$ & \\
\hline \multirow{2}{*}{$\begin{array}{l}\text { Meglitinide } \\
\text { analogues }\end{array}$} & Nateglinide & \multirow{2}{*}{\multicolumn{2}{|c|}{ No dose adjustment }} & Initiate at low dose $(60 \mathrm{mg})$ & Avoid \\
\hline & Repaglinide & & & Initiate at low dose & $0.5 \mathrm{mg})$ \\
\hline Thiazolidinediones & Pioglitazone & \multicolumn{4}{|c|}{ No dose adjustment $^{3}$} \\
\hline $\begin{array}{l}\text { Alpha-glucosidase } \\
\text { inhibitors }\end{array}$ & $\begin{array}{l}\text { Acarbose } \\
\text { Miglitol }\end{array}$ & \multicolumn{2}{|c|}{ No dose adjustment } & \multicolumn{2}{|l|}{ Avoid } \\
\hline \multirow{5}{*}{$\begin{array}{l}\text { Dipeptidyl } \\
\text { Peptidase-4 } \\
\text { Inhibitors }\end{array}$} & Sitagliptin & \multirow{4}{*}{ No dose adjustment ${ }^{4}$} & $50 \mathrm{mg} / \mathrm{day}^{4}$ & \multicolumn{2}{|l|}{$25 \mathrm{mg} /$ day } \\
\hline & Vildagliptin & & \multicolumn{3}{|c|}{$50 \mathrm{mg} /$ day $^{4}$} \\
\hline & Saxagliptin & & \multicolumn{3}{|c|}{$2.5 \mathrm{mg} / \mathrm{day}^{4}$} \\
\hline & Alogliptin & & $12.5 \mathrm{mg} /$ day $^{4}$ & \multicolumn{2}{|l|}{$6.25 \mathrm{mg} /$ day } \\
\hline & Linagliptin & \multicolumn{4}{|c|}{ No dose adjustment } \\
\hline
\end{tabular}

${ }^{1}$ Avoid if patient has other risk factors for lactic acidosis; these levels are controversial.

${ }^{2}$ Glipizide is the preferred sulfonylurea; however, safer options which carry no risk of hypoglycemia should be considered.

${ }^{3}$ Although it is not contraindicated in patients with advanced CKD, the possibility of fluid retention and bone disease may limit its use. ${ }^{4}$ Dose adjustment required for GFR $<50 \mathrm{~mL} / \mathrm{min}$.

Adapted from National Kidney Foundation, 2012 KDOQI Clinical Practice Guideline for Diabetes and CKD: 2012 Update. Am J Kidney Dis 60: 850-886. ${ }^{4}$ 
rupt their metformin treatment in the case of acute volume depletion such as gastroenteritis.

\section{Sulfonylureas}

Sulfonylureas bind to the SU receptor and close the $\mathrm{K}_{\text {ATP-dependent potassium channel in the pancreatic }}$ beta-cells, altering the resting potential of the cell. ${ }^{15}$ This leads to calcium influx and stimulation of insulin secretion. SUs are well absorbed and peak concentrations are reached within 1-4 hours. They are tightly bound to plasma albumin (90-99\%) and have a small volume of distribution. ${ }^{16}$ Since SUs stimulate insulin secretion independent of blood glucose levels, they may cause hypoglycemia, especially the long-acting SUs. ${ }^{15}$ They may also reduce hepatic gluconeogenesis and glycogenolysis and increase glucose uptake in the liver and utilization in the skeletal muscles.

Glibenclamide is a long-acting (24h) SU metabolized in the liver, mainly to 2 metabolites (M1 and M2). ${ }^{17}$ In normally functioning humans, $30-60 \%$ of M1 and M2 are excreted in the urine and the rest by biliary secretion. M1 and M2 may have a hypoglycemic effect. In a study that evaluated the pharmacokinetics of a single dose $(7 \mathrm{mg})$ of glibenclamide in patients with CKD, very small amounts of M1 and M2 were excreted in urine in the renally impaired group and diabetic patients had slightly higher serum levels of metabolites than the normal function group. ${ }^{17}$ Neither glibenclamide nor its metabolites seemed to accumulate in patients with severe CKD after a single dose of glibenclamide, which may indicate that complementary non-renal elimination routes might operate in these subjects. However, during chronic therapy one or more metabolites may accumulate in patients with CKD, resulting in an increased risk of hypoglycemia.

Glipizide is rapidly absorbed, reaching peak concentrations after 1.5 hours. ${ }^{18}$ It undergoes hepatic metabolism in several inactive metabolites and elimination $t^{1} / 2$ is $2-3$ hours. However, the duration effect of a single dose of $7.5 \mathrm{mg}$ glipizide lasts around $12-14$ hours. About $60 \%$ of glipizide is excreted as metabolites and less than $10 \%$ unchanged in urine. One study in two patients with a GFR of $30 \mathrm{ml} / \mathrm{min}$ and $10 \mathrm{ml} / \mathrm{min}$ showed an increase of the $\mathrm{t}^{1} / 2$ of glipizide metabolites to $20 \mathrm{~h}$ and more. ${ }^{19}$ Although several metabolites accumulate in patients with CKD, they do not seem to cause an increased risk of hypoglycemia. ${ }^{20}$ Of the second-generation SUs, glipizide is the preferred agent, since it does not increase the risk of hypoglycemia in patients with CKD.

Gliclazide is extensively metabolized into 7 inactive metabolites and mainly excreted in the urine. ${ }^{21}$ Renal insufficiency has little effect on the pharmacokinetic profile of gliclazide. Efficacy and safety of gliclazide modified release was evaluated in a double-blind trial over 2 years. ${ }^{22}$ Of the 507 T2DM patients who completed the study, $20 \%$ had mild to moderate $\mathrm{CKD}(\mathrm{CrCl} 20-80 \mathrm{~mL} / \mathrm{min})$ and no excess in frequency of hypoglycemia symptoms was observed in this subgroup. This was not related to a reduction in glycemic control, as final HbA1c was similar in the whole population. Gliclazide safety profile has been well established in clinical studies performed in patients with mild to moderate renal impairment.

Glimepiride is completely absorbed and undergoes extensive hepatic metabolism to the active M1 metabolite, with further dehydrogenation to the inactive M2 metabolite. ${ }^{23}$ The elimination $\mathrm{t}^{1} / 2$ is about 5-8 hours. About $37-52 \%$ of a glimepiride dose is found in the urine as M1 or M2 within 48 hours, with the remainder appearing in feces. Although glimepiride clearance tends to increase in patients with $\mathrm{CKD}$ as creatinine clearance decreases, the terminal $t^{1} 1 / 2$ is unaffected. However, urinary clearance of its metabolites decreases with creatinine clearance. ${ }^{20}$ Since prolonged hypoglycemia has been described in patients with CKD under glimepiride therapy, its use in this group of patients should be discouraged.

The recommendations for the use of SUs in patients with CKD are summarized in Table 1. Glibenclamide should be avoided in patients with moderate to severe CKD. Glipizide and gliclazide may be used in patients with CKD stages 3 to 5 without dose adjustment. Glimepiride may also be used in patients with CKD stages 3 and 4 with dose adjustment to a maximum of $1 \mathrm{mg}$ /day. However, caution must be taken in relation to the risk of hypoglycemia. Since T2DM patients with CKD often have other comorbidities and may be old and frail, safer alternatives are preferred. 


\section{Meglitinide analogues}

Meglitinide analogues stimulate insulin release by inhibiting $\mathrm{K}_{\mathrm{ATP}}$-dependent channels of the $\beta$-cell membrane. ${ }^{24}$ They are rapidly absorbed, stimulating insulin release within a few minutes, and are metabolized in the liver and mainly excreted in bile. Following preprandial administration, insulin is more readily available during and just after the meal, which leads to a reduction in postprandial hyperglycemia without the danger of hypoglycemia between meals.

Nateglinide reaches its peak plasma concentration in less than an hour. ${ }^{25}$ It binds extensively (98\%) to serum proteins and is predominantly metabolized by cytochrome P450 isoenzymes CYP2C9 (70\%) and CYP3A4 (30\%). Several metabolites have been identified in plasma and urine but only M1 has significant pharmacological activity. Most nateglinide pharmacological activity is attributed to the parent compound. ${ }^{26}$ It is rapidly eliminated with a $t^{1 / 2}$ of $2.91 \pm$ 1.84 hours. Between $20-30 \%$ of the dose is eliminated unchanged in the bile and urine. Approximately 2/3 is excreted in the feces and $1 / 3$ in urine. Nateglinide is well tolerated and has a low risk of hypoglycemia. ${ }^{27}$ In patients with CKD, a single dose of $90 \mathrm{mg}$ was safe and effective. ${ }^{28}$ Compared to healthy subjects, patients with T2DM and moderate to severe CKD ( $\mathrm{CrCl} 15-50 \mathrm{~mL} / \mathrm{min})$ displayed similar clearance, AUC, and Cmax..$^{29}$ Patients with T2DM on dialysis exhibited reduced overall drug exposure. ${ }^{30} \mathrm{~A}$ pooled analysis of elderly patients with renal impairment (n $=333$ ) did not reveal an increased incidence of confirmed hypoglycemia in this population. ${ }^{31}$ However, an increase in the levels of the active metabolite M1 occurs with decreased renal function, which may increase the risk of hypoglycemia. Evidence suggests that nateglinide may be safely used in patients with CKD stage 3, but in patients with a GFR $<30 \mathrm{~mL} /$ $\mathrm{min} / 1.73 \mathrm{~m}^{2}$ it should be initiated conservatively at $60 \mathrm{mg}$ with meals.

Repaglinide is rapidly absorbed with maximum concentrations attained within an hour. ${ }^{32}$ There is a high $(68.8 \%)$ inter-individual variation in the AUC after multiple doses in patients with T2DM that may be explained by differences in activity of CYP450 enzymes that metabolize repaglinide. It is rapidly and completely metabolized to M1 and M2. No metabolites with clinically relevant hypoglycemic effects have been identified..$^{32}$ Repaglinide is primarily eliminated by the liver and its metabolites are biliaryfecal excreted. Within 96 hours, $90 \%$ of the drug is eliminated as metabolites via the feces and $8 \%$ in the urine. Repaglinide is generally well tolerated and hypoglycemic events are rare.$^{33}$ In patients with mild to moderate $\mathrm{CKD}$, there are no clinically relevant effects in relation to the pharmacokinetics of repaglinide. In patients with T2DM and severe CKD, exposure to repaglinide appears to be elevated. Therefore, repaglinide may be safely used in CKD stage 3 , but when GFR is $<30 \mathrm{~mL} / \mathrm{min} / 1.73 \mathrm{~m}^{2}$ treatment should be started at a $0.5 \mathrm{mg}$ dose with each meal. ${ }^{34}$

\section{Thiazolidinediones}

Thiazolidinediones activate the nuclear peroxisome proliferator activated receptor- $\gamma$ (PPAR- $\gamma)$, which is thought to be involved in the modulation of the expression of genes coding for proteins involved in glucose and lipid metabolism. ${ }^{35}$ These proteins amplify the post-receptor actions of insulin in the liver and peripheral tissues, resulting in improved glycemic control with no increase in endogenous insulin secretion. ${ }^{36}$ Since rosiglitazone was withdrawn from the European market in 2010 due to its potential risk of causing ischemic heart disease and is available in the US only with significant restrictions on prescription, we will focus our discussion on pioglitazone.

Pioglitazone is well absorbed after oral administration, with peak concentrations achieved approximately 1.5 hours later. ${ }^{36} \mathrm{It}$ is highly bound to plasma proteins and has a low tissue distribution and slow elimination ( $t 1 \frac{1}{2}$ about 9 hours). It undergoes extensive hepatic metabolism and its major active metabolites, M-III and M-IV, have considerably longer terminal $\mathrm{t}^{1 / 2}$ than the parent compound. It is excreted as inactive metabolites in the feces.

A study in 21 individuals with severe $(\mathrm{CrCl}<30 \mathrm{~mL} /$ min) or moderate $(\mathrm{CrCl} 30-60 \mathrm{~mL} / \mathrm{min}) \mathrm{CKD}$ and 6 healthy volunteers receiving single and multiple doses of pioglitazone $45 \mathrm{mg}$ revealed no significant accumulation of the drug and its metabolites. ${ }^{37}$ After single and repeated oral doses, mean AUC values were decreased in patients with severe CKD compared with healthy subjects for pioglitazone, M-III and M-IV metabolites. This may be explained by reduced protein 
binding resulting in increased free pioglitazone. The tolerability and safety profile of pioglitazone was comparable between groups. In patients on hemodialysis, pioglitazone was effective and safe, with no increase in adverse effects. ${ }^{38,39}$ The most common adverse effects of pioglitazone are weight gain, fluid retention, a twofold increased risk of congestive heart failure, and an increase in fracture rates and bone loss. ${ }^{36}$ The mechanism through which thiazolidinediones induce fluid retention is controversial. Most studies suggest that this effect results from the increase in tubular sodium and water reabsorption in the kidney, but the role of specific nephron segments and sodium carriers involved is less clear. ${ }^{40}$ Some studies suggest that PPAR $\gamma$ agonist stimulates $\mathrm{Na}(+)$ reabsorption in the collecting duct by activating the epithelial $\mathrm{Na}(+)$ channel $(\mathrm{ENaC})$. Alternative mechanisms in the collecting duct include stimulation of non-ENaC sodium channel or inhibition of chloride secretion to the tubular lumen. In addition, thiazolidinediones may augment sodium reabsorption in the proximal tubule by stimulating the expression and activity of apical $\mathrm{Na}(+) / \mathrm{H}(+)$ exchanger-3 and basolateral $\mathrm{Na}(+)-\mathrm{HCO} 3(-)$ co-transporter, as well as that of $\mathrm{Na}(+) / \mathrm{K}(+)$-ATPase. These effects are mediated by PPAR $\gamma$-induced non-genomic transactivation of the epidermal growth factor receptor and downstream extracellular signal-regulated kinases (ERK). ${ }^{40}$ Therefore, pioglitazone is not recommended in New York Heart Association (NYHA) Class III and IV heart failure. ${ }^{41}$ There is also some concern about a possible association with bladder cancer. ${ }^{42}$ Although no dose adjustment in patients with CKD stages 3 to 5 is recommended, ${ }^{4}$ its use in patients with CKD should be balanced with the possibility of worsening of fluid retention and fractures, the latter particularly in patients with underlying bone disease (such as renal osteodystrophy).

\section{Alpha-glucosidase inhibitors}

The $\alpha$-glucosidase inhibitors bind reversibly to the oligosaccharide binding site of $\alpha$-glucosidases, which are enzymes located in the brush-border membrane of the small intestine responsible for the digestion of complex polysaccharides and sucrose..$^{43}$ The inhibition of $\alpha$-glucosidase delays the production of monosaccharides, reducing postprandial hyperglycemia and hyperinsulinemia. The main side effects, flatulence, abdominal distension, and diarrhea, are more frequently reported in the first 3 months of treatment and seem to be dose-dependent. ${ }^{44-46}$

Acarbose is minimally absorbed in unchanged form and has extremely limited systemic availability ${ }^{43}$ It is extensively metabolized by gastrointestinal amylases and intestinal flora, yielding at least 13 metabolites, one of which has one third of acarbose activity. In subjects with normal renal function, $35 \%$ is recovered in urine and about $50 \%$ in feces. The elimination $\mathrm{t}^{1} / 2$ is about 2.8 hours, although a more slowly declining terminal phase exists with a $\mathrm{t}^{1} / 2$ of approximately 9 hours. Patients with $\mathrm{CrCl}<25 \mathrm{~mL} / \mathrm{min} / 1.73 \mathrm{~m}^{2}$ attained peak plasma concentrations of acarbose which were about 5 times higher than volunteers with normal renal function. Their AUCs were 6 times greater than the volunteers' ${ }^{47}$ Acarbose is not recommended in patients with GFR $<26 \mathrm{~mL} / \mathrm{min} / 1.73 \mathrm{~m}^{2}{ }^{4}$

Miglitol absorption is saturable at high doses and exhibits peak concentrations in 2-3 hours. ${ }^{48}$ It is systemically absorbed rather than metabolized and it is eliminated by renal excretion as an unchanged drug. At doses higher than $25 \mathrm{mg}$, the cumulative recovery of drug from urine is lower due to the incomplete bioavailability. The elimination $t^{1} / 2$ of miglitol is approximately 2 hours. In patients with CKD, accumulation of miglitol is expected. Patients with $\mathrm{CrCl}<25 \mathrm{~mL} /$ min taking $25 \mathrm{mg} 3$ times daily exhibited a greater than two-fold increase in miglitol plasma levels compared to subjects with $\mathrm{CrCl}>60 \mathrm{~mL} / \mathrm{min}$. Little information is available on the safety of miglitol in patients with $\mathrm{CrCl}<25 \mathrm{~mL} / \mathrm{min}$. Miglitol is not recommended in patients with GFR $<25 \mathrm{~mL} / \mathrm{min} / 1.73 \mathrm{~m}^{2}{ }^{4}$

\section{Dipeptidyl peptidase-4 inhibitors}

DPP-4 inhibitors improve glycemic control by preventing the inactivation of the incretin hormones glucagon-like peptide-1 and glucose-dependent insulinotropic polypeptide. ${ }^{49}$ The increase of incretin hormones stimulates insulin secretion and reduces postprandial glucagon in a glucose-dependent fashion. The first in class was sitagliptin approved in 2006 , followed by vildagliptin in 2007, saxagliptin in 2009, alogliptin in 2010, and linagliptin in 2011. ${ }^{50}$ These drugs are not more efficient in lowering blood glucose concentrations and reducing $\mathrm{HbA} 1 \mathrm{c}$ levels than the older molecules. Nevertheless, they offer 
several clinical advantages. ${ }^{5}$ Among the most important are a negligible risk of hypoglycemia and a weight-neutral profile. These two side effects are clinically relevant since hypoglycemia is associated with increased mortality and, in patients losing weight, a $1 \%$ decrement in HbA1c was associated with an HR of $0.91(0.83,0.99)$ for the all-cause mortality endpoint. ${ }^{51}$ For participants not losing weight, each $1 \%$ decrease in $\mathrm{HbA} 1 \mathrm{c}$ was associated with an $\mathrm{HR}$ of $1.00(0.88,1,15) .^{52}$

DPP-4 inhibitors are rapidly absorbed, with significant inhibition of plasma DPP-4 activity achieved within 5 minutes of administration. ${ }^{50}$ All gliptins, except linagliptin, are poorly bound to plasma proteins.

Sitagliptin does not undergo appreciable metabolism; it produces 6 metabolites, 3 of these active, which do not seem to contribute to its pharmacodynamic profile. ${ }^{50,53}$ It is mainly excreted unchanged in the urine. A single-dose study was conducted to evaluate the pharmacokinetics of 50mg sitagliptin in patients with varying degrees of CKD compared to normal healthy controls. ${ }^{54}$ Patients with mild CKD $(\mathrm{CrCl}$ $50-80 \mathrm{~mL} / \mathrm{min}$ ) did not have a clinically meaningful increase in the plasma concentration of the drug. In patients with moderate $(\mathrm{CrCl} 30-50 \mathrm{~mL} / \mathrm{min})$ and severe CKD $(\mathrm{CrCl}<30 \mathrm{~mL} / \mathrm{min})$, and in those on hemodialysis, a 2.3-, 3.8- and 4.5-fold increase in the plasma AUC of sitagliptin was observed and the terminal $\mathrm{t}^{1} \frac{\mathrm{A}}{2}$ values were raised to $19.1,22.5$, and 28.4 hours, respectively. Sitagliptin was modestly removed by hemodialysis. In a 54-week randomized, doubleblind trial which evaluated the safety and efficacy of sitagliptin in patients with T2DM and moderate to severe CKD and ESRD on dialysis, sitagliptin was generally well tolerated and effective..$^{55}$ The overall incidence of drug-related and serious adverse effects was similar between groups. In summary, sitagliptin dose adjustments are recommended for patients with T2DM and moderate to severe renal failure $(50 \mathrm{mg} /$ day and $25 \mathrm{mg} /$ day, respectively), as for those on dialysis $(25 \mathrm{mg} /$ day $) .54,56$

Vildagliptin is extensively metabolized into a major biologically inactive metabolite and 4 minor metabolites..$^{53}$ The main route of elimination is metabolism, with only approximately $25 \%$ of the drug excreted by the kidneys. ${ }^{57}$ Vildagliptin has low po- tential for drug to drug interactions because it does not inhibit or induce CYP enzymes. ${ }^{56}$ Compared to subjects with normal renal function, in patients with mild, moderate, and severe CKD, and on hemodialysis, systemic exposure to vildagliptin was increased $\left(\mathrm{C}_{\max }\right.$ 8-66\%; AUC 32-134\%). However, changes in exposure to vildagliptin did not correlate with severity of CKD. Exposure to the main metabolite increased with increasing severity of CKD (AUC 1.6- to 6.7-fold), but this effect did not have clinically relevant consequences as the metabolite is inactive. Elimination $t^{1} / 2$ of vildagliptin was not affected by CKD. ${ }^{58}$ In a prospective study of vildagliptin $(50 \mathrm{mg}$ qd) in $515 \mathrm{~T} 2 \mathrm{DM}$ patients with moderate (GFR $\geq 30$ to $\left.\leq 50 \mathrm{~mL} / \mathrm{min} / 1.73 \mathrm{~m}^{2}\right)$ or severe CKD $(\mathrm{GFR}<30 \mathrm{~mL} /$ $\left.\min / 1.73 \mathrm{~m}^{2}\right)$, treatment with vildagliptin added to ongoing diabetic therapy was well tolerated, with a safety profile comparable to placebo.$^{59}$ A prospective, open-label, parallel group, controlled study evaluated the efficacy and safety of vildagliptin in 51 Japanese diabetic patients undergoing hemodialysis. ${ }^{60}$ After a 24-week period, no serious adverse effects such as hypoglycemia or liver impairment were observed in any patient. Vildagliptin was effective as a treatment for diabetic patients undergoing hemodialysis (decreased average $\mathrm{HbA} 1 \mathrm{c}$ levels from $6.7 \%$ baseline to $6.1 \%$, and average glycated albumin levels from $24.5 \%$ baseline to $20.5 \%, p<0.0001$ ). No dosage adjustment is required in patients with mild $\mathrm{CKD}(\mathrm{CrCl} \geq 50 \mathrm{~mL} /$ min). ${ }^{4}$ In patients with moderate or severe CKD or with ESRD, the recommended dose of vildagliptin is $50 \mathrm{mg}$ once daily. Since there is limited experience in patients on hemodialysis, vildagliptin should be used with caution in these patients.

Saxagliptin is extensively metabolized, primarily by cytochrome P450 3A4/5. ${ }^{56}$ The major metabolite (M2) has half the potency of saxagliptin. Saxagliptin and $\mathrm{M} 2$ are eliminated by hepatic and renal routes. ${ }^{61}$ In patients with mild CKD, the AUC of saxagliptin and M2 was 1.2- and 1.7- fold higher than in patients with normal renal function. ${ }^{62}$ This increase was not considered clinically relevant and no dosage adjustment is recommended. In patients with moderate or severe CKD, the AUC and M2 were up to 2.1- and 4.5- fold higher than in patients with normal renal function. A randomized 52-week trial conducted in $170 \mathrm{~T} 2 \mathrm{DM}$ patients with $\mathrm{CrCl}<50 \mathrm{~mL} / \mathrm{min}$ or 
ESRD, which evaluated the efficacy and safety of saxagliptin $2.5 \mathrm{mg}$ once daily versus placebo, showed a low frequency of mainly mild hypoglycemic events (28\% versus $29 \%$, respectively) and saxagliptin was well tolerated. ${ }^{63}$ It has recently been demonstrated that saxagliptin is able to reduce the development and progression of microalbuminuria ${ }^{64}$ Patients with moderate to severe CKD should not receive more than $2.5 \mathrm{mg} /$ day; in patients with ESRD the drug can be taken after hemodialysis. ${ }^{4,62}$

Alogliptin does not suffer appreciable metabolism and around $80 \%$ is eliminated unchanged in urine..$^{53}$ Metabolism of alogliptin is mediated by cytochrome $\mathrm{P} 450$ to active (M-I) and inactive (M-II) metabolites. The results of a single dose $(50 \mathrm{mg})$ in patients with CKD showed an increase in alogliptin exposure in comparison with healthy volunteers: approximately 1.7-, 2.1-, 3.2-, and 3.8- fold, respectively, in patients with mild, moderate, severe CKD and in patients on dialysis. ${ }^{65}$ It is advised that patients with moderate CKD should receive half of the recommended dose and patients with severe CKD or ESRD should receive a quarter of the dose. ${ }^{4}$

Linagliptin does not undergo appreciable metabolism..$^{53}$ Exposure to its major metabolite, which is inactive, was about $18 \%$ of the parent compound. A study investigating the pharmacokinetic profile of ${ }^{14} \mathrm{C}$-linagliptin demonstrated that after oral administration, $84.7 \%$ of the dose was excreted in feces, whereas renal excretion accounted for $5.4 \%$ of the dose..$^{50}$ Another study conducted in patients with and without T2DM with different degrees of CKD showed renal excretion $<7 \%$ in all groups. ${ }^{66}$ Under single-dose conditions, the degree of renal impairment did not affect plasma linagliptin concentration time profiles. Since renal excretion is a minor elimination pathway of linagliptin at therapeutic dose levels, a dose adjustment in patients with CKD is not required. ${ }^{4}$

\section{Dopamine receptor agonist}

Bromocriptine was first approved by the FDA in 1978 for the treatment of Parkinson's disease, hyperprolactinemia, and acromegaly. ${ }^{67}$ Bromocriptine has now been reformulated into a quick-release formulation for the treatment of T2DM in adults and this formulation and indication were approved by the FDA in 2009. Although its mechanism of action is unknown, bromocriptine mesylate improves postprandial glucose without increasing plasma insulin concentrations. Bromocriptine mesylate has a high bioavailability, between $65 \%$ and $95 \%$, and reaches peak plasma concentrations in 45 to 60 minutes if taken on an empty stomach, later if taken after a meal. ${ }^{68}$ It is $90-96 \%$ bound to plasma proteins and is extensively metabolized in the gastrointestinal tract and liver. The major route of bromocriptine excretion is in the bile with the remaining approximately $2-6 \%$ of an oral dose excreted via the urine. The elimination half-life is approximately 6 hours. Studies in patients with CKD are limited, ${ }^{69}$ so it should not be used in patients with reduced GFR until more evidence is available.

\section{Sodium-glucose co-transporter 2 inhibitors}

The SGLTs are a family of membrane proteins which transport glucose across the brush-border membrane of the proximal renal tubule and across the intestinal epithelium. ${ }^{70}$ SGLT1 and SGLT2 are the most studied co-transporters. Over $90 \%$ of filtered glucose is reabsorbed in the earlier segments of the proximal tubule via SGLT2; SGLT1, located in the distal segments, absorbs the remainder. ${ }^{71}$ A novel class of oral anti-diabetic drugs, the SGLT2 inhibitors, block the reabsorption of filtered glucose, leading to glycosuria with consequent glycemic control improvement. ${ }^{72}$ Dapagliflozin is the first drug in this class approved by the EMA. Improvements in glycemic parameters have been observed with dapagliflozin when administered as monotherapy, as in combination therapy, with a 10-mg dapagliflozin once-daily dose appearing to show the optimal benefit-risk profile. ${ }^{73}$ In studies that evaluated the pharmacokinetics and pharmacodynamics of dapagliflozin, it demonstrated linear pharmacokinetics over the dose range of 2.5 to $500 \mathrm{mg}$ and a dose-dependent increase in urinary glucose excretion over 24 hours. ${ }^{74}$ Dapagliflozin was rapidly absorbed after oral administration and $\mathrm{Cmax}$ were observed within $2 \mathrm{~h}$. The mean $\mathrm{t}^{1} / 2$ after the last dose ranged from 11.2 to $16.6 \mathrm{~h}$. A recent metaanalysis showed that in patie nts with moderate renal impairment, use of dapagliflozin was associated with increased incidence of renal-related adverse events. ${ }^{75}$ A multicenter trial is ongoing to evaluate the glycemic efficacy, renal safety, pharmacokinetics, and pharmacodynamics of dapagliflozin in subjects with 
T2DM and moderate CKD. ${ }^{76}$ Although renal function does not seem to be affected, ${ }^{77}$ its use in patients with moderate to severe $\mathrm{CKD}(\mathrm{CrCl}<60 \mathrm{ml} / \mathrm{min}$ or eGFR $<60 \mathrm{ml} / \mathrm{min}$ ) is not recommended. Since the elimination depends on kidney function, dapagliflozin is less effective if GFR decreases.

\section{G-protein coupled receptor 40 agonists}

G-protein coupled receptors are a superfamily of membrane proteins activated by a variety of endogenous ligands such as hormones, neurotransmitters, peptides, proteins, steroids, fatty acids (FAs), and other lipids. ${ }^{78}$ GPR 40 is a member of this family, highly expressed in pancreatic $\beta$ cells and in other insulinsecreting cell lines. FAs act as signaling molecules and have glucose-dependent insulinotropic effects mediated through activation of GPR $40 .{ }^{79}$ TAK- 875 is a novel highly selective, orally available GPR40 agonist, ${ }^{80}$ and in a study conducted in patients with T2DM it showed good tolerability with no dose-limiting side effects. ${ }^{81}$ TAK- 875 showed reductions from baseline in fasting ( 2 to $-93 \mathrm{mg} / \mathrm{dl}$ ) and post-OGTT glucose (26 to $-172 \mathrm{mg} / \mathrm{dl}$ ), with an apparent dose-dependent increase in post-OGTT C-peptide over 14 days. Consistent with preclinical data, TAK-875 apparently acts as a glucose-dependent insulinotropic drug with low hypoglycemic risk. Currently, there are no data on the safety of TAK-875 in patients with CKD.

\section{CONCLUSION}

Treating T2DM patients with CKD is a great challenge. The increasing availability of different classes of oral glucose-lowering drugs requires physicians to be aware of their mechanism of action, pharmacokinetics, and safety. In addition, the recommendations on the use of the same agent according to the degree of renal impairment may differ between countries. While in the USA the use of metformin is contraindicated in men with serum $\mathrm{Cr} \geq 1.5 \mathrm{mg} / \mathrm{dL}$ (and in women with serum $\mathrm{Cr} \geq 1.4 \mathrm{mg} / \mathrm{dL}$ ), its use is allowed in the UK until GFR of $45 \mathrm{~mL} / \mathrm{min} / 1.73 \mathrm{~m}^{2}$, with dose adjustment advised for GFR between 30-45 mL/min/1.73 $\mathrm{m}^{2}$. Although the exact GFR cutoff for metformin use to avoid lactic acidosis is controversial, the benefit of its use in patients without other risk factors for lactic acidosis seems to outweigh its risks. Sulfonylureas are not all the same. Glibenclamide should be avoided in patients with moderate to severe CKD. Glimepiride may be used in patients with CKD stages 3 and 4 with dose adjustment (1mg), but its use should be discouraged since there are less dangerous alternatives. Although glipizide and gliclazide may be used in patients with CKD stages 3 to 5 without dose adjustment, caution must be exercised due to the risk of hypoglycemia, and other classes with a safer profile should be favored. Nateglinide and repaglinide can be used in moderate to severe CKD, with dose adjustment advised for patients with GFR $<30 \mathrm{~mL} / \mathrm{min} / 1.73 \mathrm{~m}^{2}$ (nateglinide should be initiated at $60 \mathrm{mg}$ and repaglinide at $0.5 \mathrm{mg}$ dose, both with meals). Since pioglitazone is mainly hepatically eliminated, it may be used in patients with CKD in stages 3 to 5 without dose adjustment. However, caution should be taken with in regard to the development of fluid retention and worsening of bone disease. Acarbose and miglitol should not be used in patients with severe CKD. The DPP-4 inhibitors may all be used in moderate to severe CKD and in dialysis. Of these, linagliptin is the only one with insignificant renal elimination and it does not require dose adjustment. Fifty percent dose reduction is recommended for sitagliptin (50mg daily) and alogliptin $(12.5 \mathrm{mg})$ in patients with $\mathrm{CrCl} 30-50 \mathrm{~mL} /$ min and a $75 \%$ dose reduction (respectively $25 \mathrm{mg}$ and $6.25 \mathrm{mg}$ daily) for $\mathrm{CrCl}<30 \mathrm{~mL} / \mathrm{min}$. Fifty percent dose reduction is also advised for vildagliptin (50mg daily) and saxagliptin (2.5mg daily) in patients with $\mathrm{CrCl}$ $<50 \mathrm{~mL} / \mathrm{min}$. Bromocriptine mesylate is a new drug approved for the treatment of T2DM but evidence in patients with CKD is scarce, so its use should be discouraged. Emerging classes of anti-diabetic drugs are in development, such as the SGLT inhibitors and the GPR40 agonists, but there are still no data on their potential use in patients with impaired renal function.

\section{REFERENCES}

1. Souto SB, Souto EB, Braga DC, Medina JL, 2011 Prevention and current onset delay approaches of type 2 diabetes mellitus (T2DM). Eur J Clin Pharmacol 67: 653-661.

2. Packham DK, Alves TP, Dwyer JP, et al, 2012 Relative incidence of ESRD versus cardiovascular mortality in proteinuric type 2 diabetes and nephropathy: results from the DIAMETRIC (Diabetes Mellitus Treatment for Renal Insufficiency Consortium) database. Am J Kidney Dis 59: 75-83. 
3. Garg R, Williams ME, 2013 Diabetes management in the kidney patient. Med Clin North Am 97: 135-156.

4. National Kidney Foundation, 2012 KDOQI Clinical Practice Guideline for Diabetes and CKD: 2012 Update. Am J Kidney Dis 60: 850-886.

5. Inzucchi SE, Bergenstal RM, Buse JB, et al, 2012 Management of hyperglycaemia in type 2 diabetes: a patient-centered approach. Position statement of the American Diabetes Association (ADA) and the European Association for the Study of Diabetes (EASD). Diabetologia 55: 1577-1596.

6. Graham GG, Punt J, Arora M, et al, 2011 Clinical pharmacokinetics of metformin. Clin Pharmacokinet 50: 81-98.

7. UK Prospective Diabetes Study (UKPDS) Group, 1998 Effect of intensive blood-glucose control with metformin on complications in overweight patients with type 2 diabetes (UKPDS 34). Lancet 352: 854-865.

8. Lamanna C, Monami M, Marchionni N, Mannucci E, 2011 Effect of metformin on cardiovascular events and mortality: a meta-analysis of randomized clinical trials. Diabetes Obes Metab 13: 221-228.

9. Lalau JD, 2010 Lactic acidosis induced by metformin: incidence, management and prevention. Drug Saf 33: 727-740.

10. Salpeter SR, Greyber E, Pasternak GA, Salpeter Posthumous EE, 2010 Risk of fatal and nonfatal lactic acidosis with metformin use in type 2 diabetes mellitus. Cochrane Database Syst Rev 14: CD002967.

11. Sambol NC, Chiang J, Lin ET, et al, 1995 Kidney function and age are both predictors of pharmacokinetics of metformin. J Clin Pharmacol 35: 1094-1102.

12. Sibal L, Home PD, 2009 Management of type 2 diabetes: NICE guidelines. Clin Med 9: 353-357.

13. Ekstrom N, Schioler L, Svensson AM, et al, 2012 Effectiveness and safety of metformin in 51675 patients with type 2 diabetes and different levels of renal function: a cohort study from the Swedish National Diabetes Register. BMJ Open: 2(4)pii: e001076.

14. Arroyo D, Melero R, Panizo N, et al, 2011 Metforminassociated acute kidney injury and lactic acidosis. Int $\mathrm{J}$ Nephrol 2011: 749653.

15. Bryan J, Crane A, Vila-Carriles WH, Babenko AP, Aguilar-Bryan L, 2005 Insulin secretagogues, sulfonylurea receptors and K(ATP) channels. Curr Pharm Des 11: 2699-2716.

16. Shank WA Jr, Morrison AD, 1986 Oral sulfonylureas for the treatment of type II diabetes: an update. South Med J 79: 337-343.

17. Jonsson A, Rydberg T, Sterner G, Melander A, 1998 Pharmacokinetics of glibenclamide and its metabolites in diabetic patients with impaired renal function. Eur $\mathrm{J}$ Clin Pharmacol 53: 429-435.

18. Groop LC, 1992 Sulfonylureas in NIDDM. Diabetes Care 15: 737-754.

19. Balant L, Zahnd G, Gorgia A, Schwarz R, Fabre J, 1973
Pharmacokinetics of glipizide in man: influence of renal insufficiency. Diabetologia 331-338.

20. Charpentier G, Riveline JP, Varroud-Vial M, 2000 Management of drugs affecting blood glucose in diabetic patients with renal failure. Diabetes Metab 26: Suppl 4: 73-85.

21. Palmer KJ, Brogden RN, 1993 Gliclazide. An update of its pharmacological properties and therapeutic efficacy in non-insulin-dependent diabetes mellitus. Drugs 46: 92-125.

22. Drouin P, Standl E, 2004 Gliclazide modified release: results of a 2-year study in patients with type 2 diabetes. Diabetes Obes Metab 6: 414-421.

23. Langtry HD, Balfour JA, 1998 Glimepiride. A review of its use in the management of type 2 diabetes mellitus. Drugs 55: 563-584.

24. Landgraf R, 2000 Meglitinide analogues in the treatment of type 2 diabetes mellitus. Drugs Aging 17: 411-425.

25. Malaisse WJ, 2003 Pharmacology of the meglitinide analogs: new treatment options for type 2 diabetes mellitus. Treat Endocrinol 2: 401-414.

26. McLeod JF, 2004 Clinical pharmacokinetics of nateglinide: a rapidly-absorbed, short-acting insulinotropic agent. Clin Pharmacokinet 43: 97-120.

27. Ristic S, Collober-Maugeais C, Cressier F, Tang P, Pecher E, 2007 Nateglinide or gliclazide in combination with metformin for treatment of patients with type 2 diabetes mellitus inadequately controlled on maximum doses of metformin alone: 1-year trial results. Diabetes Obes Metab 9: 506-511.

28. Inoue T, Shibahara N, Miyagawa K, et al, 2003 Pharmacokinetics of nateglinide and its metabolites in subjects with type 2 diabetes mellitus and renal failure. Clin Nephrol 60: 90-95.

29. Devineni D, Walter YH, Smith HT, et al, 2003 Pharmacokinetics of nateglinide in renally impaired diabetic patients. J Clin Pharmacol 43: 163-170.

30. Available at URL: http://www.accessdata.fda.gov/drugsatfda_docs/label/2011/021204s014lbl.pdf (Accessed 06/09/2013).

31. Del Prato S, Heine RJ, Keilson L, et al, 2003 Treatment of patients over 64 years of age with type 2 diabetes: experience from nateglinide pooled database retrospective analysis. Diabetes Care 26: 2075-2080.

32. Culy CR, Jarvis B, 2001 Repaglinide: a review of its therapeutic use in type 2 diabetes mellitus. Drugs 61: 1625-1660.

33. Scott LJ, 2012 Repaglinide: a review of its use in type 2 diabetes mellitus. Drugs 72: 249-272.

34. Schumacher S, Abbasi I, Weise D, et al, 2001 Singleand multiple-dose pharmacokinetics of repaglinide in patients with type 2 diabetes and renal impairment. Eur J Clin Pharmacol 57: 147-152.

35. Lehmann JM, Moore LB, Smith-Oliver TA, et al, 1995 An antidiabetic thiazolidinedione is a high affinity ligand for peroxisome proliferator-activated receptor gamma 
(PPAR gamma). J Biol Chem 270: 12953-12956.

36. Gillies PS, Dunn CJ, 2000 Pioglitazone. Drugs 60: 333-345.

37. Budde K, Neumayer HH, Fritsche L, et al, 2003 The pharmacokinetics of pioglitazone in patients with impaired renal function. Br J Clin Pharmacol 55: 368-374.

38. Abe M, Kikuchi F, Okada K, Kaizu K, Matsumoto K, 2008 Efficacy of pioglitazone on type 2 diabetic patients with hemodialysis. Diabetes Res Clin Pract 80: 432-438.

39. Abe M, Kikuchi F, Okada K, Matsumoto K, 2009 Plasma concentration of pioglitazone in patients with type 2 diabetes on hemodialysis. Ther Apher Dial 13: 238-239.

40. Beltowski J, Rachanczyk J, Wlodarczyk M, 2013 Thiazolidinedione-induced fluid retention: recent insights into the molecular mechanisms. PPAR Res 2013: 628628.

41. Available at URL: http://www.accessdata.fda.gov/ drugsatfda_docs/label/2011/021073s043s044lbl.pdf (Accessed 06-09-2013).

42. Azoulay L, Yin H, Filion KB, et al, 2012 The use of pioglitazone and the risk of bladder cancer in people with type 2 diabetes: nested case-control study. BMJ 344: e3645.

43. Clissold SP, Edwards C, 1988 Acarbose. A preliminary review of its pharmacodynamic and pharmacokinetic properties, and therapeutic potential. Drugs 35: 214-243.

44. Mertes G, 2001 Safety and efficacy of acarbose in the treatment of Type 2 diabetes: data from a 5-year surveillance study. Diabetes Res Clin Pract 52: 193-204.

45. Neuser D, Benson A, Bruckner A, et al, 2005 Safety and tolerability of acarbose in the treatment of type 1 and type 2 diabetes mellitus. Clin Drug Investig 25: 579-587.

46. Segal P, Eliahou HE, Petzinna D, et al, 2005 Long-term efficacy and tolerability of acarbose treatment in patients with type 2 diabetes mellitus. Clin Drug Investig 25: 589-595.

47. Available at URL: http://www.accessdata.fda.gov/drugsatfda_docs/label/2012/020482s025lbl.pdf (Accessed 10-08-2012).

48. Available at URL: http://www.accessdata.fda.gov/drugsatfda_docs/label/2012/020682s0101bl.pdf (Accessed 23-08-2012).

49. Nauck MA, 2011 Incretin-based therapies for type 2 diabetes mellitus: properties, functions, and clinical implications. Am J Med 124: S3-18.

50. Baetta R, Corsini A, 2011 Pharmacology of dipeptidyl peptidase-4 inhibitors: similarities and differences. Drugs 71: 1441-1467.

51. Duckworth W, Abraira C, Moritz T, Reda D, Emanuele N, Reaven PD, Zieve FJ, Marks J, Davis SN, Hayward R, Warren SR, Goldeman S. Mc Carren M, Vitek ME, Henderson WG, Huang GD, VAIDT Investigators., 2009 Glucose control and vascular complications in veterans with type 2 diabetes. N Engl J Med 360: 129-139.

52. Andersson C, van Gaal L, Caterson ID, et al, 2012
Relationship between HbA1c levels and risk of cardiovascular adverse outcomes and all-cause mortality in overweight and obese cardiovascular high-risk women and men with type 2 diabetes. Diabetologia 55: 23482355 .

53. Deacon CF, 2011 Dipeptidyl peptidase-4 inhibitors in the treatment of type 2 diabetes: a comparative review. Diabetes Obes Metab 13: 7-18.

54. Bergman AJ, Cote J, Yi B, et al, 2007 Effect of renal insufficiency on the pharmacokinetics of sitagliptin, a dipeptidyl peptidase-4 inhibitor. Diabetes Care 30: 1862-1864.

55. Chan JC, Scott R, Arjona Ferreira JC, et al, 2008 Safety and efficacy of sitagliptin in patients with type 2 diabetes and chronic renal insufficiency. Diabetes Obes Metab 10: 545-555.

56. Scheen AJ, 2010 Pharmacokinetics of dipeptidylpeptidase-4 inhibitors. Diabetes Obes Metab 12: 648-658.

57. He H, Tran P, Yin H, et al, 2009 Absorption, metabolism, and excretion of [14C]vildagliptin, a novel dipeptidyl peptidase 4 inhibitor, in humans. Drug Metab Dispos 37: 536-544.

58. Scheen AJ, 2012 DPP-4 inhibitors in the management of type 2 diabetes: a critical review of head-to-head trials. Diabetes Metab 38: 89-101.

59. Lukashevich V, Schweizer A, Shao Q, Groop PH, Kothny W, 2011 Safety and efficacy of vildagliptin versus placebo in patients with type 2 diabetes and moderate or severe renal impairment: a prospective 24-week randomized placebo-controlled trial. Diabetes Obes Metab 13: 947-954.

60. Ito M, Abe M, Okada K, et al, 2011 The dipeptidyl peptidase-4 (DPP-4) inhibitor vildagliptin improves glycemic control in type 2 diabetic patients undergoing hemodialysis. Endocr J 58: 979-987.

61. Dhillon S, Weber J, 2009 Saxagliptin. Drugs 69: 21032114.

62. Boulton DW, Li L, Frevert EU, et al, 2011 Influence of renal or hepatic impairment on the pharmacokinetics of saxagliptin. Clin Pharmacokinet 50: 253-265.

63. Nowicki M, Rychlik I, Haller H, et al, 2011 Long-term treatment with the dipeptidyl peptidase-4 inhibitor saxagliptin in patients with type 2 diabetes mellitus and renal impairment: a randomised controlled 52-week efficacy and safety study. Int J Clin Pract 65: 1230-1239.

64. Scirica BM, Bhatt DL, Braunwald E, et al, 2013 Saxagliptin and Cardiovascular Outcomes in Patients with Type 2 Diabetes Mellitus. N Engl J Med 369: 1317-1326.

65.Scott LJ, 2010 Alogliptin: a review of its use in the management of type 2 diabetes mellitus. Drugs 70: 2051-2072.

66. Graefe-Mody U, Friedrich C, Port A, et al, 2011 Effect of renal impairment on the pharmacokinetics of the dipeptidyl peptidase-4 inhibitor linagliptin(*). Diabetes Obes Metab 13: 939-946.

67. Valiquette G, 2011 Bromocriptine for diabetes mellitus 
type II. Cardiol Rev 19: 272-275.

68. Available at URL: http://www.accessdata.fda.gov/ drugsatfda_docs/label/2009/020866lbl.pdf (Accessed 06-09-2013).

69. Mejia-Rodriguez O, Herrera-Abarca JE, CeballosReyes G, et al, 2013 Cardiovascular and renal effects of bromocriptine in diabetic patients with stage 4 chronic kidney disease. Biomed Res Int 2013: 104059.

70. Hummel CS, Lu C, Loo DD, et al, 2011 Glucose transport by human renal $\mathrm{Na}+/ \mathrm{D}$-glucose cotransporters SGLT1 and SGLT2. Am J Physiol Cell Physiol 300: C14-21.

71. Wright EM, 2001 Renal $\mathrm{Na}(+)$-glucose cotransporters. Am J Physiol Renal Physiol 280: F10-18.

72. Nair S, Wilding JP, 2010 Sodium glucose cotransporter 2 inhibitors as a new treatment for diabetes mellitus. J Clin Endocrinol Metab 95: 34-42.

73. Kim Y, Babu AR, 2012 Clinical potential of sodiumglucose cotransporter 2 inhibitors in the management of type 2 diabetes. Diabetes Metab Syndr Obes 5: 313-327.

74. Komoroski B, Vachharajani N, Boulton D, et al, 2009 Dapagliflozin, a novel SGLT2 inhibitor, induces dosedependent glucosuria in healthy subjects. Clin Pharmacol Ther 85: 520-526.

75. Vasilakou D, Karagiannis T, Athanasiadou E, et al, 2013 Sodium-Glucose Cotransporter 2 Inhibitors for Type 2
Diabetes: A Systematic Review and Meta-analysis. Ann Intern Med 159: 262-274.

76. Available at URL: http://clinicaltrials.gov/ct2/show/ NCT00663260 (Accessed 04-06-2013).

77. Bailey CJ, Gross JL, Pieters A, Bastien A, List JF, 2010 Effect of dapagliflozin in patients with type 2 diabetes who have inadequate glycaemic control with metformin: a randomised, double-blind, placebo-controlled trial. Lancet 375: 2223-2233.

78. Kebede MA, Alquier T, Latour MG, Poitout V, 2009 Lipid receptors and islet function: therapeutic implications? Diabetes Obes Metab 11: Suppl 4: 10-20.

79. Rayasam GV, Tulasi VK, Davis JA, Bansal VS, 2007 Fatty acid receptors as new therapeutic targets for diabetes. Expert Opin Ther Targets 11: 661-671.

80. Araki T, Hirayama M, Hiroi S, Kaku K, 2012 GPR40induced insulin secretion by the novel agonist TAK-875: first clinical findings in patients with type 2 diabetes. Diabetes Obes Metab 14: 271-278.

81. Leifke E, Naik H, Wu J, et al, 2012 A multiple-ascendingdose study to evaluate safety, pharmacokinetics, and pharmacodynamics of a novel GPR40 agonist, TAK875 , in subjects with type 2 diabetes. Clin Pharmacol Ther 92: 29-39. 